\title{
Le récepteur de l'acide rétinoïque : un nouveau venu dans la famille
}

Le rétinol (vitamine A) et son dérivé, l'acide rétinoïque, interviennent dans le contrôle de la différenciation cellulaire et dans la croissance des cellules épithéliales. L'acide rétinoïque inhibe la prolifération de certains types de cellules malignes et, récemment, il a été proposé qu'il pourrait être le morphogène intervenant dans la différenciation de l'aile chez le poulet $\left(\mathrm{m} / \mathrm{s} n^{\circ} 8\right.$, vol. 3, p. 492). Alors que de nombreux effets du rétinol peuvent être dus à son dérivé, il semble être lui-même indispensable à la vision des couleurs et à la spermatogenèse. Les deux molécules sont prises en charge dans le cytoplasme par des protéines de liaison différentes, puis sont transloquées dans le noyau où elles sont alors transférées sur des récepteurs nucléaires dont la concentration est extrêmement faible en comparaison de celle des protéines de liaison cytoplasmiques, ce qui a toujours empêché leur purification. Deux équipes [1, 2] viennent d'identifier des clones d'ADNc codant pour le récepteur de l'acide rétinoïque. La stratégie de l'équipe de Pierre Chambon [1] fut de cribler des banques d'ADNc à l'aide d'un oligonucléotide reproduisant un motif d'ADN particulièrement bien conservé dans toutes les régions $C$ (de liaison à l'ADN) des messagers de récepteurs d'hormones stéroïdes et thyroïdiennes $\left(\mathrm{m} / \mathrm{s} \mathrm{n} n^{\circ} 3\right.$, vol. 3, p. 172). Le laboratoire de Ronald M. Evans utilisa, quant à lui, un oligonucléotide dérivé de la séquence publiée par Anne Dejean et al. [3], du laboratoire de Pierre Tiollais, et correspondant à la région $C$ d'un gène localisé au niveau du site d'intégration d'un virus de l'hépatite $B$ dans un hépatocarcinome humain [3]. La démonstration que les clones iso- de l'acide rétinoïgue fut faite grâce à deux types d'expériences: (a) tout d'abord, l'analyse de l'affinité pour l'acide rétinoïque de la protéine produite par expression des séquences clonées; (b) ensuite, la constitution d'un récepteur hybride comportant les régions $\mathrm{A}, \mathrm{B}$ et $\mathrm{C}$ du récepteur des estrogènes [1] ou des glucocorticoïdes [2] et la région $\mathrm{E}$ du présomptif récepteur de l'acide rétinoïque. Les régions $\mathrm{C}$ de liaison à l'ADN confèrent à la molécule la spécificité de liaison au niveau des promoteurs stimulés par les estrogènes ou les glucocorticoïdes, alors que la région $\mathrm{E}$, domaine de liaison de l'hormone, détermine la nature du ligand stimulant. De fait, l'acide rétinoïque stimule la transcription de gènes contrôlés par des séquences de réponse aux stéroïdes (estrogènes ou glucocorticoïdes) lorsqu'ils sont cotransférés dans des cellules avec un vecteur gouvernant l'expression du récepteur hybride. La molécule du récepteur de l'acide rétinoïque ressemble aux autres récepteurs nucléaires déjà caractérisés, ceux des stéroïdes, des hormones thyroïdiennes et de la vitamine D. Les similitudes de la région $\mathrm{C}$ avec celles des récepteurs des hormones thyroïdiennes et de l'oncogène $v$-erb $A$ sont plus marquées qu'avec celles des hormones stéroïdes, indiquant qu'il existe au moins deux types de récepteurs de cette famille, pour les stéroïdes d'une part, pour les autres molécules d'autre part. La moitié $\mathrm{N}$ terminale de cette région $\mathrm{C}$ est pratiquement identique à celle du gène détecté à proximité du site d'intégration d'un virus de l'hépatite $B$ dans le laboratoire de Pierre Tiollais [3].

Dans des conditions d'hybridation peu «stringentes» (favorisant la reconnaissance entre des séquences homologues non iden- tiques), l'aspect des Southern blots révélés avec les ADNc clonés permet de prévoir l'existence d'une famille multigénique, comme cela a été montré récemment pour les gènes $c$-erb $A$ codant pour de présomptifs récepteurs des hormones thyroïdiennes [4].

Plusieurs récepteurs nucléaires, appartenant probablement à la même super-famille que les récepteurs étudiés ici, restent à caractériser, notamment ceux des androgènes, du rétinol et de xénobiotiques comme la dioxine. $\mathrm{La}$ stratégie résumée plus haut - la création d'une molécule hybride contenant la région de liaison à l'ADN de récepteurs dont les cibles sont connues et la région de liaison de «l'hormone» inconnue - devrait permettre de tester systématiquement ces hypothèses. Le rôle joué par l'acide rétinoïque dans le contrôle de la prolifération de certaines cellules suggère qu'une altération de son récepteur pourrait avoir des conséquences oncogéniques. Peut-être un phénomène de ce type explique-t-il la constitution d'un hépatocarcinome en cas d'altération d'un gène de cette famille par insertion virale à proximité [3].

A.K.

1. Petkovich M, Brand NJ, Krust A, Cham bon $P$. A human retinoic acid receptor which belongs to the family of nuclear receptors. Nature 1987 ; 330 : 444-50.

2. Giguere V, Ong ES, Segui P, Evans RM. Identification of a receptor for the morphogen retinoic acid. Nature 1987; 330 : 624-9.

3. Dejean A, Bouguelret L, Grzeschik $\mathrm{KH}$ Tiollais P. Hepatitis B virus DNA integration in a sequence homologous to v-erbA and steroid receptor genes in a hepatocellular carcinoma. Nature $1986 ; 322$ : 70-2.

4. Thompson CC, Weinberger C, Lebo R Evans RM. Identification of a novel thyroid hormone receptor expressed in the mammalian central nervous system. Science 1987 $237: 1610-4$ 